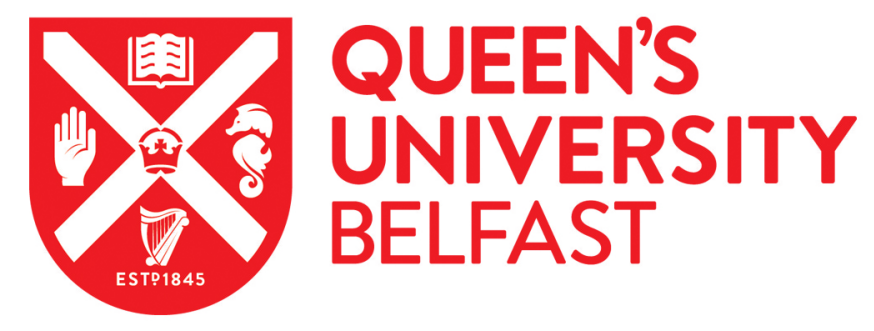

\title{
Impact of variation in cancer registration practice on observed international cancer survival differences between International Cancer Benchmarking Partnership (ICBP) jurisdictions
}

Eden, M., Harrison, S., Griffin, M., Lambe, M., Pettersson, D., Gavin, A., Brewster, D. H., Lin, Y., Johannesen, T. B., Milne, R. L., Farrugia, H., Nishri, D., King, M-J., Huws, D. W., Warlow, J., Turner, D., Earle, C. C., Peake, M., \& Rashbass, J. (2019). Impact of variation in cancer registration practice on observed international cancer survival differences between International Cancer Benchmarking Partnership (ICBP) jurisdictions. Cancer Epidemiology, 58, 184-192. https://doi.org/10.1016/j.canep.2018.10.019

Published in:

Cancer Epidemiology

Document Version:

Peer reviewed version

Queen's University Belfast - Research Portal:

Link to publication record in Queen's University Belfast Research Portal

\section{Publisher rights}

Copyright 2019 Elsevier Ltd.

This manuscript is distributed under a Creative Commons Attribution-NonCommercial-NoDerivs License

(https://creativecommons.org/licenses/by-nc-nd/4.0/), which permits distribution and reproduction for non-commercial purposes, provided the author and source are cited

\section{General rights}

Copyright for the publications made accessible via the Queen's University Belfast Research Portal is retained by the author(s) and / or other copyright owners and it is a condition of accessing these publications that users recognise and abide by the legal requirements associated with these rights.

\section{Take down policy}

The Research Portal is Queen's institutional repository that provides access to Queen's research output. Every effort has been made to ensure that content in the Research Portal does not infringe any person's rights, or applicable UK laws. If you discover content in the Research Portal that you believe breaches copyright or violates any law, please contact openaccess@qub.ac.uk. 


\section{What proportion of observed international cancer survival differences could be attributed to differences in cancer registration practice - an investigation between jurisdictions in the International Cancer Benchmarking Partnership}

\section{Authors}

Michael Eden*, (Michael.Eden@phe.gov.uk), National Cancer Registry and Analysis Service (NCRAS), England, UK Samantha Harrison*, (Samantha.harrison@cancer.org.uk), Policy and Information, Cancer Research UK, England, UK Michelle Griffin, (michelle.griffin@phe.gov.uk), National Disease Registration, Public Health England, England, UK Mats Lambe, (mats.lambe@ki.se) Department of Medical Epidemiology and Biostatistics, Karolinska Institutet, Sweden

David Pettersson, (david.pettersson@socialstyrelsen.se) National Board of Health and Welfare, Stockholm, Sweden Anna Gavin, (a.gavin@qub.ac.uk), N. Ireland Cancer Registry, Queen's University Belfast, Northern Ireland David H. Brewster, (david.brewster@nhs.net), Scottish Cancer Registry, NHS National Services Scotland, Scotland, UK

Yulan Lin (yulan.lin@ntnu.no), European Palliative Care Research Centre (PRC), Department of Cancer Research and Molecular Medicine Norwegian University of Science and Technology (NTNU), Norway

Tom B. Johannesen (tom.borge.johannesen@kreftregisteret.no), Cancer Registry of Norway, Oslo, Norway Roger L. Milne (roger.milne@cancervic.org.au), Cancer Epidemiology and Intelligence Division, Cancer Council Victoria, Melbourne, Australia

Helen Farrugia (helen.farrugia@cancervic.org.au), Victorian Cancer Registry, Cancer Council Victoria, Melbourne, Australia

Diane Nishri (Diane.Nishri@cancercare.on.ca), Prevention and Cancer Control, Cancer Care Ontario, Ontario, Canada Mary-Jane King (MaryJane.King@cancercare.on.ca), Ontario Cancer Registry, Cancer Care Ontario, Ontario, Canada Dyfed W Huws (dyfed.huws@wales.nhs.uk), Welsh Cancer Intelligence and Surveillance Unit, Public Health Wales, Wales, UK

Janet Warlow (janet.warlow@wales.nhs.uk), Welsh Cancer Intelligence and Surveillance Unit, Public Health Wales, Wales, UK

Donna Turner (Donna.Turner@cancercare.mb.ca), Epidemiology and Cancer Registry, CancerCare Manitoba, Manitoba, Canada

Craig Earle (craig.earle@ices.on.ca), Institute for Clinical Evaluative Sciences, Ontario Institute for Cancer Research, Ontario, Canada

Michael Peake (mick.peake@uhl-tr.nhs.uk), Respiratory Medicine, University of Leicester and National Cancer Registration and Analysis Service (NCRAS), England, UK

Jem Rashbass (Jem.Rashbass@phe.gov.uk), National Disease Registration, Public Health England, England, UK

Manuscript: 3484 words, 6 tables, 3 supplementary files, $\mathbf{2}$ figures

*first author 


\begin{abstract}
International cancer survival comparisons use cancer registration data to report one-year survival, a metric which informs the development of cancer policies and practices. International comparisons, like the International Cancer Benchmarking Partnership (ICBP), must understand how registration differences impact on survival estimates prior to drawing conclusions.
\end{abstract}

Key informants reported differences in registration practice for capturing date of diagnosis, death certificate case handling and registration of multiple primary tumours. Sensitivity analyses estimated their impact using baseline and supplementary cancer registration data from England and Sweden. The impact of registration differences on oneyear survival estimates is reported.

Depending on tumour site and jurisdiction, the largest differences between unadjusted (estimates from previous ICBP survival data) and adjusted (estimates recalculated taking into account differences in registration) one-year survival, were 1.3\% (breast), 3.4\% (colorectal), 7.3\% (lung) and 2.6\% (ovary).

Survival estimates for four jurisdictions are affected by this adjustment: New South Wales, Norway, Ontario and Sweden. Sweden and Ontario's one-year survival lowered after adjustment, but they remained jurisdictions with the highest survival for breast and ovarian cancer respectively. Victoria and Manitoba had the highest adjusted one-year lung cancer survival estimate at 42.7\%, compared to Sweden's highest unadjusted estimate of $43.6 \%$ (adjusted to $39.0 \%)$. For colorectal cancer, Victoria's highest survival estimate of $85.1 \%$ remained unchanged after adjustment.

Population-based cancer survival comparisons can be subject to detection and registration biases that can account for part of the survival gap reported between jurisdictions. Efforts should be made to apply consistent registration practices internationally. In the meantime, survival comparisons should provide clear notice of the registration biases affecting survival comparisons or take account of and adjust for differences in cancer registration. 


\section{ICBP Module 5 - Workstream 1, Part 2}

\section{Introduction}

Many countries have established population-based cancer registries to collect and record various cancer data. These are an essential resource to measure the burden of cancer and inform cancer control policies and clinical practices. Therefore, the quality and comparability of data collected is fundamental for effective cancer control planning.

Internationally agreed standards for data collection and classification have been in existence for many years [1-4]. Variation between these standards does exist, for example, the International Agency for Research on Cancer (IARC) and the European Network of Cancer Registries (ENCR) have different rules and hierarchies for defining the date of diagnosis $[5,6]$. Previous studies have noted differences in the availability, collection, processing and recording of data, which affects both incidence and survival [7].

International cancer survival comparisons, such as the International Cancer Benchmarking Partnership (ICBP), use cancer registration data to report one-year survival, among other outcome metrics [8-10]. One-year survival is often used as a proxy for early and late diagnosis, with higher one-year survival suggesting earlier diagnosis [11]. Compared to five-year survival estimates, estimations of one-year survival are much more sensitive to the availability of data and differences in registration practice. This is because changing a diagnosis date by one month, for example, produces a greater proportional change in survival time when assessed over one-year compared to five years.

The differences in definitions and handling of data underlying survival estimates may lead to bias and misleading comparisons. For example, differences in date of diagnosis definition have the potential to introduce lead-time bias and inflate one-year survival estimates by increasing the calculated time survived. This has been recognised by EUROCOURSE (EUROpe against Cancer: Optimisation of the Use of Registries for Scientific Excellence in research); a European network that explores the differences in the quality, usage and output of cancer registries and aims to improve their use through information exchange and sharing of best practice [12].

Death certificate case handling also has the potential to influence survival. Processing starts with death certificate initiated $(\mathrm{DCl})$ cases where cancer is mentioned on a death certificate and the registry has no other information on the patient. Where additional information is available, cases are fully registered and would be included in survival analyses. In cases where no additional information is available or where death notifications are not investigated cases are categorized as death certificate only (DCO) registrations - these are routinely excluded from international survival analyses [8-10]. A high proportion of DCO cases in a population will tend to artificially improve one-year survival estimates. Conversely, where efforts have been made to trace data on these cases, their inclusion in registries will lower one-year survival as DCl cases usually have a very short survival $[7,13]$.

Multiple tumours in a patient can be classified according to the order in which they arise, with the first defined as ' $1{ }^{\text {st }}$ order', the second as ' $2^{\text {nd }}$ order' and so on. Rules for how multiple primaries are registered (e.g. the inclusion/exclusion of $2^{\text {nd }}$ order tumours) can influence survival estimates as $2^{\text {nd }}$ order primaries tend to have worse one-year survival and excluding them from a cancer register would artificially improve one-year survival calculations $[14]$.

While there have been studies which have assessed the impacts of cancer registry practice among fewer countries and on fewer cancer types, [15-16] to date no-one has attempted to assess and estimate the combined effects of these differences in cancer registration practices on one-year survival on an international scale. This study aimed to estimate to what extent isolated and combined differences in cancer registration practices between participating ICBP jurisdictions contributed to variations in international survival at one year.

\section{Methods \\ Key informant exercise}

A key informant exercise was undertaken to assess differences in cancer registration practices between ICBP jurisdictions, notably differences in the definition of date of diagnosis, death certificate case handling and registration of multiple primary tumours. The cancer sites studied were breast, colorectal, lung and ovarian cancer. 
ICBP Module 5 - Workstream 1, Part 2

The jurisdictions included England, Wales, Scotland, Northern Ireland (the UK), Sweden, Denmark, Norway, Victoria (Australia), Manitoba and Ontario (Canada). Scotland, though unable to participate in the ICBP survival benchmark, was included in this exercise as assumptions and analyses in this study are likely to be applicable. We used a framework developed by Parkin and Bray, 2009 to assess the comparability of registry data [18, 19]. A summary of relevant findings and framework is available in Supplementary Material 1.

\section{Sensitivity analyses}

Sensitivity analyses assessed the impact of registration differences on one-year survival using information from key informants (Supplementary material 1), baseline and supplementary cancer registration data from England and Sweden. Analyses focused on the three areas with potential to impact on one-year survival: definition of date of diagnosis, registration of multiple primaries and death certificate case handling. We report the impact of differences in cancer registration practices on one-year survival for each area, and then all three combined.

Baseline data underlying the sensitivity analysis were taken from the East of England region of the English National Cancer Registration and Analysis Service (NCRAS).

NCRAS data was used as a baseline because it provided corroborated data for date of death and multiple time points for incidence date. This enabled the most accurate possible calculations of one-year survival and provided a valid baseline. To investigate the impact of death certificate handling practices in Sweden, data from the Swedish Patient Register and the Swedish Cancer Registry were also used in sensitivity analyses.

NCRAS data included the same tumour sites and used the same protocol as the ICBP survival benchmark [8]. The analysis used tumours ${ }^{1}$ diagnosed in 2010 and followed up to May 2014, with the exception of the analysis of multiple primaries which required longer follow-up times and used tumours diagnosed in 19966 and followed up to 2012.

\section{Supplementary data}

Baseline data from NCRAS was linked to additional information from records in the NHS Hospital Episode Statistics (HES) and Cancer Waiting Times (CWT) datasets. Baseline data linked to clinical sources were used to carry out 'casestudy' sensitivity analyses for each area of cancer registration practice where data were available and applicable.

For the analysis of death certification practice, Swedish data from the Patient Register and Swedish Cancer Registry databases were used.

\section{Definition of date of diagnosis}

We assumed a similar proportion of registrations could be assigned an earlier date of diagnosis across jurisdictions. This assumption was tested by using data, from NCRAS and Sweden's Cancer Registry, the National Board of Health and Welfare, Stockholm (2010 incidence data for breast, colorectal, lung and ovarian cancer) respectively.

One-year survival was calculated using the different dates available in the baseline data. Date of diagnosis based upon pathological confirmation of cancer was used to calculate the baseline measurement, consistent with ENCR guidelines [6]. Other definitions of date of diagnosis were then selected and one-year survival compared with the baseline.

Estimates prioritising the date of diagnosis in primary care used two methods: the first only included cases diagnosed within 6 months of the baseline date; the second used all cases including those diagnosed greater than 6 months from the baseline date ${ }^{2}$.

\section{Death certificate case handling}

\footnotetext{
${ }^{1}$ Information available on these tumours included diagnosis date, gender, age, morphology code, topography code, DCO and $\mathrm{DCl}$ status, registry integrated stage and where available, clinical, radiological and pathological stage, neo-adjuvant chemotherapy status and date of death.

${ }^{2}$ This was done to simulate the practice of some registries in the ICBP (Supplementary Material 1).
} 
ICBP Module 5 - Workstream 1, Part 2

Analyses using the baseline date (pathology based diagnosis date prioritised) were performed with and without inclusion of the DCO cases. All jurisdictions except for Sweden were able to supply their proportion of DCOs (more information available in Supplementary Material 3).

We investigated death certificates in Sweden arising in 2008-2012 that mentioned ICBP tumour sites that were unmatched to the cancer registry database. Unmatched DCOs were then 'traced-back' using information from the records of the Patient Register not routinely available in Swedish cancer registration practice. The Patient Register contains information on hospital activities but does not include records from primary care [20]. Where enough information was available from the Patient Register to provide supporting evidence of a date of diagnosis for the cancer mentioned on the death certificate, the case was categorised as a DCl and added to the cohort of registered tumours in the Cancer Registry for that tumour site. The impact of the addition of DCls on one-year survival was reported.

\section{Registration of multiple primaries}

Prior to 2010, all participating registries except Ontario $^{3}$ registered multiple primary tumours in accordance with IARC guidelines [21] that could be any tumour excluding non-melanoma skin cancer. Based on IARC Guidelines, $2^{\text {nd }}$ or higher-order primary tumours could be registered if they occurred at a different anatomical site, or at the same topographical site providing they were not from the same tumour group (e.g. adenocarcinoma, lymphoma etc.) as the preceding tumour(s) [21]. The analysis of registration of multiple primary tumours was performed by first calculating for the average proportion of $2^{\text {nd }}$ or higher-order primaries registered in Ontario. This was then compared to the highest percentage of registered $2^{\text {nd }}$ or higher-order primaries from the other Canadian registries that participated in the ICBP [8].

The $1^{\text {st }}, 2^{\text {nd }}, 3^{\text {rd }}$ etc. diagnosed tumours for each patient were identified from the NCRAS cohort. For the same tumour sites used in the ICBP benchmark [8], one-year survival estimates were calculated both including and excluding $2^{\text {nd }}$ or higher order primary tumours. The percentage point difference in one-year survival between including and excluding $2^{\text {nd }}$ or higher-order primaries was calculated and then adjusted by the average proportion described above for the four tumour sites. This estimated the effect on one-year survival calculations, based on registration practice in Ontario.

\section{Results}

\section{Key Informant exercise}

Differences in the definition of date of diagnosis, death certificate case handling and registration of multiple primary tumours were highlighted as areas with the potential to impact on one-year survival estimates. Key informants also reported differences in cancer registration that did not impact or had a negligible effect on survival calculations (e.g. staging systems).

\section{Definition of date of diagnosis}

The IARC and the ENCR rules and hierarchies for the defining date of diagnosis by participating jurisdictions are displayed [Figure 1]. Prioritisation of definitions for the date of diagnosis varied, with many registries prioritising diagnosis dates that typically occur before histological confirmation. However, it is acknowledged that for some cancers histological information is not always available (e.g. patient and presentation characteristics, influence whether a lung tumour is histologically confirmed).

\section{ADD FIGURE 1 HERE}

\footnotetext{
Footnote

${ }^{3}$ Previously the Ontario Cancer Registry Information System (OCRIS) did not permit registration of a second tumour of the same body site, laterality was not recognized, and a subsequent cancer of the same histology type was not counted as a new primary. Subsequent primaries that were of a different body part, and were not the same histology were almost always counted as new primaries, although with constraints present because the core cancer identification logic used ICD-9. From 2010 onwards, Ontario started using a Surveillance, Epidemiology and End Results (SEER) based system for the registration of multiple primaries that allowed for the registration of $2^{\text {nd }}$ or higher-order primaries at different anatomical sites (22).
} 


\section{Death certificate case handling}

Some jurisdictions investigate DCOs and add information gathered from clinical data sources. Access and availability to these data sources are reported to vary [Supplementary Material 1]. All jurisdictions, except Sweden and Ontario, have a central source from which death certificates can be received and investigated. For legal reasons, trace-back of DCO cases on a routine basis is not possible in Sweden, whilst Ontario will not actively trace back cases as long as their DCO proportion is less or equal to $2 \%$ (in line with national targets).

Registration of multiple primaries - only Ontario reported variance from other areas in registration of multiple tumours.

\section{Sensitivity analyses}

\section{Definition of date of diagnosis}

Using NCRAS and Swedish Cancer Registry data, we found that a similar proportion of registrations using earlier dates of diagnosis could change in each cancer registry, validating our earlier assumption. Within the NCRAS data, $46.5 \%$ of registrations would have an earlier date of diagnosis when prioritising a clinical diagnosis date over the date of histological confirmation compared with $45.0 \%$ in the Swedish data.

The largest differences in one-year survival were seen when prioritising date of diagnosis based on date seen in primary care [Table 1]. The differences in one-year survival were greatest for lung cancer (which increased by 7.3 percentage points), and lowest for breast cancer ( 0.8 percentage points).

\section{ADD TABLE 1 HERE}

\section{Death certificate case-handling}

Jurisdictions reported annual DCO proportions after all other cases had been traced back (data collected in April 2014, N/A in Sweden). Proportions of DCO varied from 0.3\% (Scotland, Northern Ireland), 0.5\% (Manitoba), 1.0\% (Norway), 1.4\% (New South Wales and Wales), 1.7\% (Victoria) and 2.0\% (Ontario, no active trace back if DCO proportion less than or equal to $2 \%$ ) and $2.6 \%$ (England, regional variation $0.1 \%$ to $4.1 \%$ ).

Excluding DCOs from the NCRAS baseline data resulted in small increases (0.1 percentage points) in one-year survival estimates for breast and colorectal cancer (Table 2). The small increases were due to the low DCO proportion in the NCRAS, East of England, indicating many cases are "traced back" to produce DCI registrations.

\section{ADD TABLE 2 HERE}

When death certificate trace back is performed on Swedish data, an overall decrease in one-year survival is observed for colorectal, lung and ovarian tumours (Table 3). In Sweden the effect of excluding DCOs registered with unknown primaries and secondary cancers had a greater impact on one-year survival estimates for ovarian cancer than for lung and colorectal cancer. Further investigation revealed that the primary tumour site stated on the death certificate in some cases was different to that recorded in the patient register (e.g. mesothelioma and lung cancers). The analysis excluded DCOs that were not confirmed to be the relevant primary tumour.

\section{ADD TABLE 3 HERE}

\section{Registration of multiple primaries}

Ontario had a significantly lower percentage of $2^{\text {nd }}$ or higher-order primaries recorded in their registry compared to other Canadian registries (Table 4). This was statistically significant for all four ICBP tumour sites (Z-test, $p=<0.01$ ).

\section{ADD TABLE 4 HERE}

Excluding patients diagnosed with $2^{\text {nd }}$ or higher-order primary tumours in the NCRAS data from 1996-2012 reduced one-year overall survival by 1.2-6.2 percentage points for $2^{\text {nd }}$ and higher order primaries, compared to $1^{\text {st }}$ order primaries only (Table 5). 
ICBP Module 5 - Workstream 1, Part 2 ADD TABLE 5 HERE 
ICBP Module 5 - Workstream 1, Part 2

\section{ADD TABLE 6 HERE}

\section{ADD FIGURE 2 HERE}

\section{Summary of sensitivity analyses}

Figures from Table 1 are used to calculate percentage point change in diagnosis date, Swedish DCO inclusion figures are taken from Table 3, and figures from multiple primaries inclusion are taken from Table 5 . The changes to the estimated survival using this method were most pronounced in colorectal and lung cancers. Depending on tumour site and jurisdiction, the largest differences between unadjusted (survival estimates from previous ICBP survival data) and

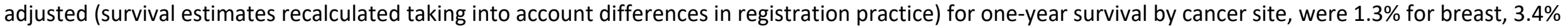
for colorectal, $7.3 \%$ for lung and $2.6 \%$ for ovary.

The one-year survival estimates for New South Wales, Norway, Ontario and Sweden were affected by this adjustment. While the adjusted one-year survival was lower for Sweden and Ontario, they were still the jurisdictions with the highest survival for breast and ovarian cancer respectively. For lung cancer, after adjustment, Victoria and Manitoba had the highest adjusted one-year survival estimate at 42.7\%, compared to Sweden's previous highest unadjusted estimate of $43.6 \%$, and adjusted of $39.0 \%$. For colorectal cancer, Victoria's estimate of $85.1 \%$ was not changed by the adjustment and remained the highest amongst the jurisdictions included.

This adjustment reduces the survival gap between the jurisdictions with the original highest one-year survival and the lowest (Wales for all four cancer types) by $8.7 \%$ for breast, $30.0 \%$ for lung, $0.0 \%$ for colorectal and $13.6 \%$ for ovarian. 


\section{ICBP Module 5 - Workstream 1, Part 2}

\section{Discussion}

In an effort to estimate the impact of differences in cancer registration practices on international comparisons of one-year survival, we performed analyses using information from cancer registry key informants, and baseline and supplementary cancer registration data.

Prioritising earlier events for the date of diagnosis ahead of the date of the histology leads to increases in one-year survival that were most marked when jurisdictions prioritised the date of first diagnosis by a physician. The effect was greatest for lung and colorectal cancers ( 7.3 and 3.4 percentage points respectively). The magnitude of the change was dependent upon the proportion of cases that had a date of diagnosis available that was significantly earlier than the date of histological confirmation. This reflects the typical patient pathway for the diagnosis of colorectal and lung cancer [23, 24], with a period of weeks to months of clinical investigations prior to the definitive histological confirmation. Patient or presentation characteristics may also influence histological confirmation. This contrasts with breast cancer pathways in all jurisdictions that ensure there is a minimal lag time between clinical and pathological diagnosis of cancer [23, 25-26].

Though routinely excluded from international survival comparisons, previous studies have demonstrated the impact of inclusion of DCOs on survival for particular registries and regions. Robinson et al. (2007) showed five-year relative survival for colorectal, lung, breast and ovarian cancers decreased by 4 to 14 percentage points by including DCO cases [7].

Not using death certification for case ascertainment, as occurs in Sweden [27-30], was found to have a significant impact on one-year survival estimates. The Association of the Nordic Cancer Registries (NORDCAN) has identified this as one possible cause for lower incidence rates, especially in older patients and for more lethal tumours, resulting in higher survival estimates because incident cases with short survival may have been excluded [31].

The death certificate trace back simulation using Swedish data, showed a significant reduction in one-year survival in colorectal, lung and ovarian cancers (-3.3, -3.5 and -2.8 percentage points respectively). This may reflect the typical pathway of lung and ovarian cancers where many patients present with late stage disease and are too unwell to undergo diagnostic tests to confirm cancer diagnosis. Although ovarian cancer data for Sweden was not included in the ICBP survival benchmark, these results may impact other international survival comparisons where ovarian cancer survival is reported for Sweden $[9,10]$.

Excluding DCOs registered in Sweden had the greatest impact on one-year survival estimates for ovarian cancer. Further investigation found that the primary tumour site on some death certificates was shown to be incorrect following matching of the case in the Patient Register. Our findings add weight to challenges associated with the reliability of death certificate data when used to assign incidence only [32, 33]. We did not explore the impact of the accuracy of death certificate reporting, but trace-back procedures have been shown to improve the completeness, reliability and comparability of registry data.

The exclusion of $2^{\text {nd }}$ or higher order tumours with similar morphology to the first-order tumour as seen in Ontario, leads to the exclusion of cases with less favourable survival outcomes therefore inflating one-year survival in Ontario. A study by Heinavaara et al. 2002, showed that overall relative survival for $2^{\text {nd }}$ order primaries was worse than those with a respective single cancer only [33]. This was quantified in a study by Brenner et al. 2005, showing that for the tumour sites analysed in ICBP, the exclusion of $2^{\text {nd }}$ and higher order primaries increased five-year relative survival in the 1993-7 cohort by an average of 1 percentage point [34]. Buiatti et al. looked at the incidence of second primary cancers in Italian cancer registries. They identified an increased risk for developing rectal cancer in breast cancer patients and an increased risk of developing ovarian cancer in female colorectal cancer patients [35]. Therefore, exclusion of second or higher order primaries in the four tumour sites studied here, would be expected to more selectively reduce the number of rectal and ovarian cancers in female patients with a first order breast or colorectal cancers. 


\section{ICBP Module 5 - Workstream 1, Part 2}

The EUROCARE working group also studied the impact of the inclusion of patients with multiple cancers on five-year survival, for all cancers combined the average difference was $-0.4 \%$ in women and $-0.7 \%$ in men, with variation by cancer site and the proportion of multiple primaries [14]. From 2010 onwards, Ontario started using a SEER based system for the registration of multiple primaries that allowed for the registration of $2^{\text {nd }}$ or higher-order primaries at different anatomical sites [22].

\section{Strengths and limitations}

To our knowledge this study is the first to estimate the impact of multiple cancer registration differences on international cancer survival comparisons.

A strength of the sensitivity analysis was the use of parameters based on cancer registry data that in some areas incorporated data from multiple jurisdictions, combined with information on day-to-day cancer registration practice [Supplementary Material 1].

Properties of the baseline data from NCRAS that underpinned the sensitivity analysis were assumed to be like baseline data that could have been collected from other jurisdictions. This was based on the comparability of the jurisdictions in the criteria outlined in the methods, including equality of case ascertainment between registries. To validate this assumption future research could obtain more data from different jurisdictions to add to the baseline data.

Investigating the impact that varying availability of data sources, have on short-term survival estimates requires analysis of diagnostic and treatment processes that are often not exclusive to cancer across various medical, surgical and diagnostic disciplines, and an assessment of the quality of these data sources, which is more suited to a high-resolution study.

The analysis was limited by the complexity of interaction between areas of cancer registration practice that affect comparability identified by Parkin and Bray 2009, in particular the availability of data sources and their impact on selecting a date of diagnosis [19]. The differences in one-year survival following adjustment for cancer registration practice should be interpreted with carefully. For example, we assumed that definition of a pathological confirmation was consistent across jurisdictions, though it is acknowledged that the date could refer to the date of specimen collection, laboratory receipt or report authorisation date [5, 34].

\section{Conclusion}

We show that differences in cancer registration practices impact international comparisons of one-year survival. Changes in one-year survival varied across jurisdictions and cancer types, dependant on registration practices locally. In the original survival estimates Sweden had the highest one-year survival for breast and lung cancer, Victoria for colorectal cancer and Ontario for ovarian cancer. It is important to note that after adjustments were made, these jurisdictions still had the highest survival estimates with the exception of Sweden for lung cancer. Cancer registration differences can account for part of the survival gap reported between jurisdictions.

Population-based cancer survival comparison results can be adversely affected by registration and detection biases which have been particularly highlighted in Sweden and Ontario. Efforts should be made ahead of international comparisons to assess differences in cancer registration practices and their potential impact on cancer outcomes, extending also to other tumour sites such as kidney and lymphoma. To this end, Norway, Wales, Sweden and England are taking steps to collect multiple sources of data such as different dates of diagnosis based on ENCR definitions. Future international comparison studies, should address registration and detection biases by using these multiple sources of data and the findings of this study to assist the interpretation of differences in one-year cancer survival or provide appropriate warnings about biases with accompanying data on incidence and mortality. 


\section{ICBP Module 5 - Workstream 1, Part 2}

With international agreement, it may be possible to use the results of the sensitivity analysis to foster transparency with regards to the standardisation of registry data. Alongside this we acknowledge the rapidly evolving nature of cancer registries and as such any agreement would need to evolve at similar pace. Phase 2 of the ICBP will use this analysis and insight from key informants as a framework for future analysis of cancer registration protocols, as it expands to cover further tumour sites.

\section{Acknowledgements}

The authors would like to thank, Martine Bomb, Brad Groves, Samantha Harrison, Irene Reguilon and Deborah Robinson of Cancer Research UK for managing the ICBP programme, who have been key to bringing about the development of this paper.

The authors would also like to acknowledge and thank those who contributed to data collection, interpretation and review of our results and this paper. We received input from the:

Programme Board: Ole Andersen (Danish Health and Medicines Authority, Denmark), Søren Brostrøm (Danish Health and Medicines Authority, Denmark), Heather Bryant (Canadian Partnership Against Cancer, Canada), David Currow (Cancer Institute New South Wales, Australia), Sri Navaratnam (CancerCare Manitoba, Canada), Anna Gavin (Northern Ireland Cancer Registry, UK), Gunilla Gunnarsson (Swedish Association of Local Authorities and Regions, Sweden), Jane Hanson (Public Health Wales, UK), Todd Harper (Cancer Council Victoria, Australia), Stein Kaasa (Norwegian University of Science and Technology, Norway), Aileen Keel (Scottish Government, UK) Nicola Quin (Cancer Council Victoria, Australia), Nicole Mittmann (Cancer Care Ontario, Canada), Michael A Richards (Care Quality Commission, UK), Michael Sherar (Cancer Care Ontario, Canada), Robert Thomas (Department of Health, Victoria, Australia), Kathryn Whitfield (Department of Health, Victoria Australia).

Module 5 working group: Michael Eden, Michelle Griffin, Jem Rashbass, Eva Morris, Mick Peake, Margreet Luchtenborg, Victoria Coupland, Daniela Tateru (Public Health England); Deirdre Fitzpatrick, (Northern Ireland); Dyfed W Huws, Janet Warlow, Ceri White (Wales); David H Brewster, Andy Deas (Scotland); AnneKari Knudsen, Yulan Lin, Bjørn Møller (Norway); Donna Turner (Manitoba); Craig Earle, Mary-Jane King, Diane Nishri (Ontario); Lorraine Shack (Alberta); Roger Milne, Luc te Marvelde (Victoria); Deborah Baker, Richard Walton (New South Wales).

Funding: This study was supported primarily by NHS England, with additional contributions from Cancer Control Alberta, Cancer Institute NSW, Norwegian Directorate of Health, Cancer Care Ontario, Scottish Government, Cancer Council Victoria, Public Health Wales, Northern Ireland Cancer Registry, Public Health Agency for Northern Ireland, Tenovus Cancer Care, and Danish Cancer Society.

Module 5 Academic Reference Group: Henrik Møller (King's College London, UK), Paul Lambert (University of Leicester, UK), Paul Dickman (Karolinska Institute, Sweden), Hannah Weir (Centre for Disease Control and Prevention, Atlanta, USA

\section{References}

1. Jensen OM, Parkin DM, MacLennan R, Muir CS and Skeet RG. Cancer Registration: Principles and Methods. Lyon: International Agency for Research on Cancer 1991: 294p

2. Young JL Jr, Roffers SD, Ries LAG, Fritz AG, Hurlbut AA. SEER Summary Staging Manual - 2000: Codes and Coding Instructions. NIH Pub. No. 01-4969. Bethesda: National Cancer Institute, 2001: 299p 


\section{ICBP Module 5 - Workstream 1, Part 2}

3. European Network of Cancer Registries [Internet]. [accessed $24^{\text {th }}$ August]. Available from: https://www.iarc.fr/en/publications/pdfs-online/treport-pub/treportpub40/IARC Technical Report No40.pdf

4. North American Association of Central Cancer Registries [Internet]. [cited 2016 Apr 19]. Available from: www.naaccr.org

5. MacLennan R. Items of patient information which may be collected by registries. In: Jensen OM, Parkin DM, MacLennan R, Muir CS and Skeet RG. Cancer Registration: Principles and Methods. Lyon: International Agency for Research on Cancer 1991: 43-64

6. Pheby D, Martínez C, Roumagnac M, Schouten LJ. Recommendations for coding Incidence Date. Ispra, Italy: European Network of Cancer Registries 1997. Available from:

http://www.encr.eu/index.php/activities/recommendations, accessed 25 August 2016

7. Robinson D, Sankila R, Hakulinen T, Møller H. Interpreting international comparisons of cancer survival: the effects of incomplete registration and the presence of death certificate only cases on survival estimates. Eur J Cancer 2007; 43(5):909-13.

8. Coleman MP, Forman D, Bryant H, Butler J, Rachet B, Maringe C, Nur U, Tracey E, Coory M, Hatcher J, McGahan CE, Turner D, Marrett L, Gjerstorff ML, Johannesen TB, Adolfsson J, Lambe M, Lawrence G, Meechan D, Morris EJ, Middleton R, Steward J, Richards MA. Cancer survival in Australia, Canada, Denmark, Norway, Sweden, and the UK, 1995-2007 (the International Cancer Benchmarking Partnership): an analysis of population-based cancer registry data. Lancet 2011, 377; 127-138

9. De Angelis RD, Sant M, Coleman MP, Francisci S, Baili P, Pierannunzio D, Trama A, Visser O, Brenner H, Ardanaz E, Bielska-Lasota M, Engholm G, Nennecke A, Siesling S, Berrino F, Capocaccia R, the EUROCARE-5 working group. Cancer survival in Europe 1999-2007 by country and age: results of EUROCARE-5 - a population based study. The Lancet Oncology 2014 15(1) 23-24

10. Allemani C, Weir HK, Carreira H, Harewood R, Spika D, Wang XS Bannon F, Ahn JV, Johnson CJ, Bonaventure A, Marcos-Gragera R, Stiller C, Azevedo e Silva G, Chen WQ, Ogunbiyi OJ, Rachet B, Soeberg MJ, You H, Matsuda T, Bielska-Lasota M, Storm H, Tucker TC, Coleman MP, the CONCORD Working Group. Global surveillance of cancer survival 1995-2009: analysis of individual data for 25 676887 patients from 279 population-based registries in 67 countries (CONCORD-2). Lancet 2015; 385(9972): 977-1010

11. Thomson CS and Forman D. Cancer Survival in England and the influence of early diagnosis: what can we learn from recent EUROCARE results? Br J Cancer 2009;101 Suppl 2:s102-9

12. EUROCOURSE (EUROpe against Cancer: Optimisation of the Use of Registries for Scientific Excellence in research). https://eurl-ecvam.jrc.ec.europa.eu/glossary/glossary/eurocourse . Last accessed March 2018.

13. Pollock AM, Vickers $N$. The impact on colorectal cancer survival of cases registered by "death certificate only": implications for national survival rates. Br. J. Cancer 1994, 70:1229-1231.

14. Rosso S, De Angelis RD, Ciccolallo L, Carrini E, Soerjomataram I, Grande E, Zigon G, Brenner H, the EUROCARE Working Group. Multiple tumours in survival estimates. European Journal of Cancer (2009) 45; 1080-1094

15. Woods LM, Coleman MP, Lawrence G, Rashbass J, Berrino F, Rachet B. Evidence against the proposition that "UK cancer survival statistics are misleading": simulation study with National Cancer Registry data. BMJ 2011;342:d3399

16. Moller H, Richards S, Hanchett N, Riaz SP, Lüchtenborg M, Holmberg L, et al. Completeness of case ascertainment and survival time error in English cancer registries: impact on 1-year survival estimates. Br J Cancer. 2011 Jun 28;105(1):170-6.

17. Rutherford MJ, Moller H, Lambert PC. A comprehensive assessment of the impact of errors in the cancer registration process on 1- and 5-year relative survival estimates. Br J Cancer. 2013 Feb 19;108(3):691-8. 


\section{ICBP Module 5 - Workstream 1, Part 2}

18. Bray F, Parkin DM. Evaluation of data quality in the cancer registry: Principles and methods. Part I: Comparability, validity and timeliness. Eur. J. Cancer 2009; 747-755

19. Parkin DM, Bray F. Evaluation of data quality in the cancer registry: Principles and methods Part II. Completeness. Eur. J. Cancer 2009; 756-764

20. Socialstyrelsen - Information available on the National Patient Registry http://www.socialstyrelsen.se/SiteCollectionDocuments/information-in-the-national-patientregister.pdf Accessed online 25th August 2016

21. International Agency for Research on Cancer. Available from: http://www.iacr.com.fr/images/doc/MPrules july2004.pdf - to update Last accessed November 2017.

22. Bethesda MD, Johnson $\mathrm{CH}$, Peace $\mathrm{S}$, Adamo P, Fritz A. The 2007 multiple primary and histology coding rules. National Cancer Institute; 2007.

23. Lyratzopoulos G, Saunders CL, Abel GA, McPhail S, Neal RD, Wardle J, Rubin GP. The relative length of the patient and the primary care interval in patients with 28 common and rarer cancers. $\mathrm{Br} J$ Cancer 2015; 112:S35-40.

24. Barrett J, Hamilton W. Pathways to the diagnosis of lung cancer in the UK: a cohort study. BMC Fam Pract 2008; 9:31.

25. Yarnold J. Early and Locally Advanced Breast Cancer: Diagnosis and Treatment National Institute for Health and Clinical Excellence 2009. Clinical Oncology 2009; 21(3):159-60

26. Hansen RP, Vedsted P, Sokolowski I, Søndergaard J, Olesen F. Time intervals from first symptom to treatment of cancer: a cohort study of 2,212 newly diagnosed cancer patients. BMC Health Serv Res. BioMed Central 2011; 11(1):284

27. Official Statistics of Sweden. Cancer Incidence in Sweden 2010. Socialstyrelsen, 2011: 100p Available from: http://www.socialstyrelsen.se/lists/artikelkatalog/attachments/18530/2011-12-15.pdf Last accessed November 2017.

28. Mattsson B, Wallgren A. Completeness of the Swedish Cancer Register. Non-notified cancer cases recorded on death certificates in 1978. Acta Radiol Oncol 1984; 23(5):305-13.

29. Mattsson B, Rutqvist LE, Wallgren A. Undernotification of Diagnosed Cancer Cases to the Stockholm Cancer Registry. Int. J. Epidemiol 1985; 14(1): 64-69

30. NORDCAN - Association of the Nordic Cancer Registries. News, errors and warnings. Available from: http://www-dep.iarc.fr/NORDCAN/english/news.htm

31. Lund JL, Harlan LC, Yabroff KR, Warren JL. Should Cause of Death from the Death Certificate Be Used to Examine Cancer-Specific Survival? A Study of Patients with Distant Stage Disease. Cancer Invest (2010) 28(7): 758-764.

32. Laurenti R, Coleman MP, Aylin P. Accuracy of statements of the cause of death on death certificates and the international comparability of mortality statistics. In: Coleman MP and Aylin P. Death certification and mortality statistics: an international perspective, series SMPS No. 64 . London: The Stationary Office 2000;1-9

33. Heinävaara S, Sankila R, Storm H, Langmark F, Hakulinen T. Relative survival of patients with prostate cancer as a first or subsequent tumor - a Nordic collaborative study. Cancer Causes Control. Kluwer Academic Publishers; 2002;13(9):797-806.

34. Brenner $\mathrm{H}$, Hakulinen T. Population-based monitoring of cancer patient survival in situations with imperfect completeness of cancer registration. Br J Cancer. 2005 Feb 14;92(3):576-9.

35. Buiatti E, Crocetti E, Acciai S, Gafh L, Falcini F, Milandri C, La Rosa M (1997) Incidence of Second Primary Cancers in Three Italian Population-based Cancer Registries. European Journal of Cancer. 1997 April; 33 (11): 1829-1834 
ICBP Module 5 - Workstream 1, Part 2

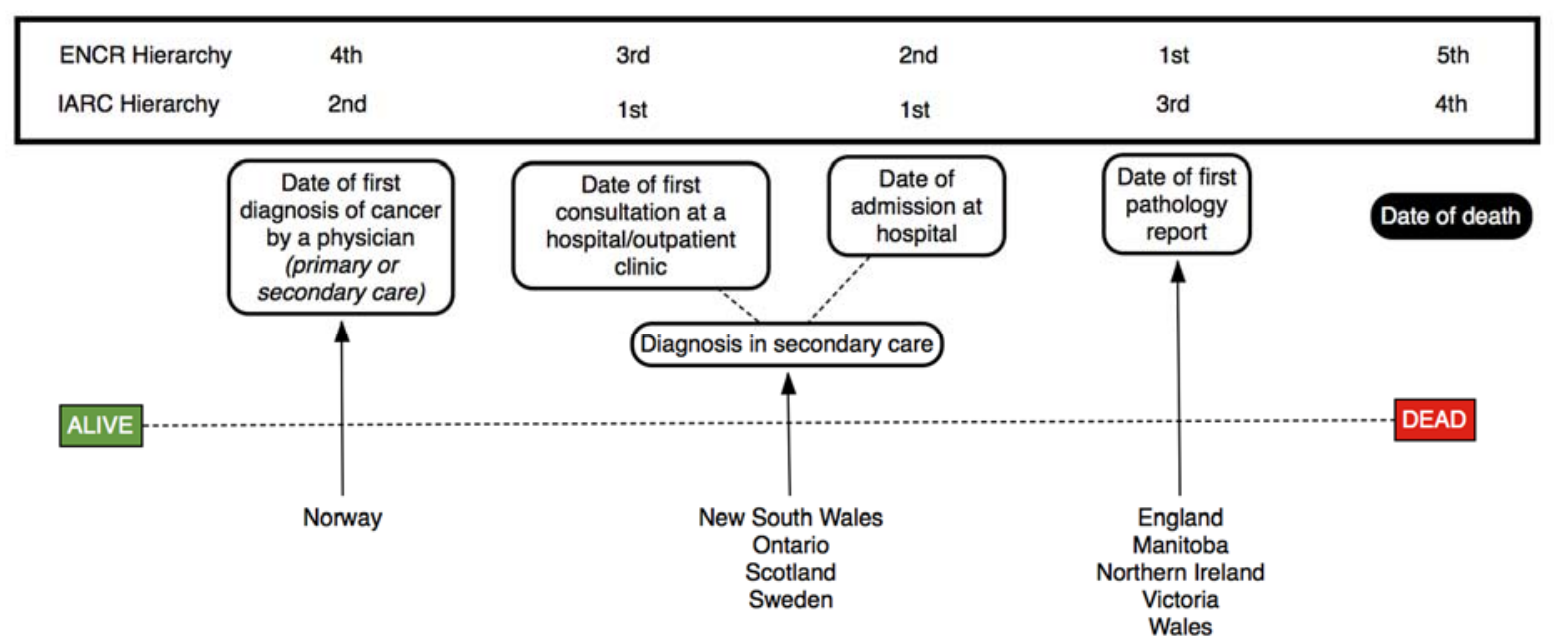

Figure 1. Illustration of prioritised source of incidence date by jurisdiction. Information collected April 2014. 
$\underline{\text { Tables }}$

From 'Impact of variation of cancer registration practice on observed international cancer survival differences between the jurisdictions of the ICBP

(International Cancer Benchmarking Partnership)'

Table 1:

\begin{tabular}{|c|c|c|c|c|c|}
\hline & \multicolumn{5}{|c|}{ Prioritised Incidence Date } \\
\hline & $\begin{array}{l}\text { Date of first } \\
\text { pathology report } \\
\text { (Baseline) }\end{array}$ & $\begin{array}{l}\text { Date of first } \\
\text { imaging report }\end{array}$ & $\begin{array}{l}\text { Date of first } \\
\text { consultation / } \\
\text { admission to } \\
\text { hospital }\end{array}$ & $\begin{array}{l}\text { Date first referred } \\
\text { to secondary care }\end{array}$ & $\begin{array}{l}\text { Date of first diagnosis b } \\
\text { physician (excluding dat } \\
\text { more than } 6 \text { months } \\
\text { before the baseline) }\end{array}$ \\
\hline Breast & $93.6(92.9,94.3)$ & $\begin{array}{r}93.7(93.0,94.4) \\
(+0.1) \\
{[+1]}\end{array}$ & $\begin{array}{r}93.7(93.0,94.4) \\
(+0.1) \\
{[+9]}\end{array}$ & $\begin{array}{r}93.8(93.1,94.5) \\
(+0.2) \\
{[+16]}\end{array}$ & $\begin{array}{r}93.8(93.1,94 \\
1+0 \\
{[+}\end{array}$ \\
\hline Lung & $29.4(27.9,30.9)$ & $\begin{array}{r}29.7(28.2,31.2) \\
(+0.3) \\
{[+3]}\end{array}$ & $\begin{array}{r}30.5(29.0,32.0) \\
(+1.1) \\
{[+15]}\end{array}$ & $\begin{array}{r}30.8 \text { (29.3., 32.3) } \\
(+1.4) \\
{[+16]}\end{array}$ & $\begin{array}{r}31.3(29.8,32 \\
(+1 \\
{[+}\end{array}$ \\
\hline Ovary & $67.1(63.1,70.8)$ & $\begin{array}{r}67.2(63.3,70.9) \\
(+0.1) \\
{[+1]}\end{array}$ & $\begin{array}{r}67.6(63.7,71.3) \\
(+0.5) \\
{[+1]}\end{array}$ & $\begin{array}{r}67.9(64.0,71.6) \\
(+0.8) \\
{[+5]}\end{array}$ & $\begin{array}{r}67.9 \text { (64.0, } 71 \\
1+0 \\
{[+}\end{array}$ \\
\hline
\end{tabular}

Table $1 .{ }^{4}$ One-year overall survival (\%) with $95 \%$ confidence intervals, prioritised by different incidence date definitions for the four tumour sites studied. Percentage point differences in second parentheses. Change in median days survived compared to baseline in square brackets. Using data from NCRAS, Eastern Office 2010.

Table 2:

\begin{tabular}{|l|r|r|l|l|}
\hline DCO Cases & \multicolumn{1}{|l|}{ Breast } & \multicolumn{1}{l|}{ Colorectal } & \multicolumn{1}{l|}{ Lung } & \multicolumn{1}{l|}{ Ovary } \\
\hline Excluded & $93.7(93.0,94.4)$ & $73.3(71.9,74.6)$ & $29.5(28.0,31.0)$ & $67.1(63.1,70.8)$ \\
\hline Included & $93.6(92.9,94.3)$ & $73.2(71.8,74.5)$ & $29.4(27.9,30.9)$ & $67.1(63.1,70.8)$ \\
\hline
\end{tabular}

Table 2. One-year overall survival (\%) with 95\% confidence intervals by tumour site based on inclusion or exclusion of DCO cases, NCRAS, East of England region 2010 data.

\footnotetext{
${ }^{4}$ In a separate analysis of the Swedish data only, comparing the incidence dates from date of first pathology and date of first consultation, changed the median days survived by tumour site, by +2 days for breast and colorectal, +15 days for lung and 0 days for ovary.
} 
Table 3:

\begin{tabular}{|c|c|c|c|c|}
\hline Tumour Site & $\begin{array}{l}\text { Number of } \\
\text { Registered cases in } \\
\text { Cancer Register } \\
\text { (Group A) }\end{array}$ & $\begin{array}{l}\text { Number of death certificates } \\
\text { with correct tumour registerable } \\
\text { from Patient Register (Group B) }\end{array}$ & $\begin{array}{l}\text { Combined total of } \\
\text { Group A and B }\end{array}$ & $\begin{array}{l}\text { One-year survival } \\
\text { (Group A) }\end{array}$ \\
\hline Breast & 33,855 & 237 & 34,092 & $96.0 \%$ \\
\hline Colorectal & 28,205 & 1,561 & 29,766 & $80.6 \%$ \\
\hline Lung & 18,504 & 2,891 & 21,395 & $43.9 \%$ \\
\hline Ovary & 3,855 & 263 & 4,118 & $81.6 \%$ \\
\hline
\end{tabular}

Table 3. One-year overall survival for Swedish 2008-2012 cases comparing cases only registered in cancer register and combined registered and unregistered cases. Percentage point difference in brackets.

(National Board of Health and Welfare, Stockholm, Sweden)

Table 4:

\begin{tabular}{|l|l|l|l|l}
\hline & \multicolumn{4}{|l}{} \\
& \% of adults (15-99 years) diagnosed during 1995-2007 whose cancer was a $2^{\text {nd }}$ or higher-orc \\
\hline & Breast & Colorectal & Lung & Ovary \\
\hline Alberta & 8.7 & 13.0 & 14.5 & 12.0 \\
\hline
\end{tabular}


ICBP Module 5 - Workstream 1, Part 2

\begin{tabular}{|l|l|l|l|l|}
\hline British Columbia & 9.9 & 14.6 & 14.7 & 10.4 \\
\hline Manitoba & 11.0 & 14.8 & 17.9 & 13.5 \\
\hline Ontario & 4.9 & 8.1 & 8.7 & 8.5 \\
\hline $\begin{array}{l}\text { Proportion recorded in } \\
\text { Ontario compared to } \\
\text { highest }\end{array}$ & $44.5 \%$ & $54.7 \%$ & $48.6 \%$ & $62.9 \%$ \\
\hline
\end{tabular}

Table 4. Percentage of adults diagnosed during 1995-2007 whose cancer was a second or higher-order primary by cancer and jurisdiction (5).

Table 5:

\begin{tabular}{|l|l|l|l|l}
\hline & \multicolumn{2}{|c|}{ \% One-year overall survival } & & \\
\hline & $\begin{array}{l}1^{\text {st }} \text { order tumours } \\
\text { only }\end{array}$ & $\begin{array}{l}\mathbf{1}^{\text {st }} \text { or higher order } \\
\text { tumours }\end{array}$ & $\begin{array}{l}\text { Percentage point } \\
\text { difference }\end{array}$ & $\begin{array}{l}\text { Percentage point difference multip } \\
\text { average proportion recorded in Tak }\end{array}$ \\
\hline Breast & 92.1 & 89.5 & 2.6 & 1.2 \\
\hline Colorectal & 86.8 & 83.4 & 3.4 & 1.9 \\
\hline Lung & 68.7 & 55.9 & 12.8 & 6.2 \\
\hline Ovary & 85.8 & 83.0 & 2.8 & 1.8 \\
\hline
\end{tabular}

Table 5. Comparison of one-year overall survival between $1^{\text {st }}$ order only and $1^{\text {st }}$ or higher order tumours.

(NCRAS East of England region 1996-2012 data).

\begin{tabular}{|c|c|c|c|c|c|c|c|c|}
\hline & & & & Percentag & point cha & Ige by regis & ation practice & \\
\hline & $\begin{array}{l}\text { Jurisdictio } \\
\mathrm{n}\end{array}$ & $\begin{array}{l}\text { Unadjusted } \\
\text { original } \\
\text { survival by } \\
\text { jurisdiction } \\
\text { (Q) }\end{array}$ & $\begin{array}{l}\text { Original } \\
\text { Survival } \\
\text { Gap } \\
\text { (\% } \\
\text { Points) } \\
\text { (M=Q-A) }\end{array}$ & $\begin{array}{l}\text { Definition } \\
\text { of } \\
\text { incidence } \\
\text { date }(X)\end{array}$ & \begin{tabular}{|l} 
DCO \\
Inclusio \\
$n$ \\
$(Y)$
\end{tabular} & $\begin{array}{l}\text { Multiple } \\
\text { primary } \\
\text { inclusion } \\
\text { (Z) }\end{array}$ & $\begin{array}{l}\text { \% Point } \\
\text { Change } \\
(P=X+Y+Z)\end{array}$ & $\begin{array}{l}\text { Adjusted } \\
\text { estimated one- } \\
\text { year survival (\%) } \\
\mathrm{N}=\mathrm{Q}-\mathrm{P}\end{array}$ \\
\hline Breast & & & & & & & & \\
\hline Wales & England & 94.3 & 0.9 & - & - & - & - & 94.3 \\
\hline & Manitoba & 96.7 & 3.3 & - & - & - & - & 96.7 \\
\hline Original & NSW & 96.5 & 3.1 & 0.1 & - & - & 0.1 & 96.4 \\
\hline one-year & NI & 95.0 & 1.6 & - & - & - & - & 95.0 \\
\hline
\end{tabular}


ICBP Module 5 - Workstream 1, Part 2

\begin{tabular}{|c|c|c|c|c|c|c|c|c|}
\hline \multirow{4}{*}{$\begin{array}{l}\text { survival: } \\
93.4 \%(A)\end{array}$} & Norway & 96.6 & 3.2 & 0.9 & - & - & 0.9 & 95.7 \\
\hline & Ontario & 96.1 & 2.7 & 0.1 & - & 1.2 & 1.3 & 94.8 \\
\hline & Sweden & 98.0 & 4.6 & 0.1 & 0.3 & - & 0.4 & 97.6 \\
\hline & Victoria & 97.1 & 3.7 & - & - & - & - & 97.1 \\
\hline \multicolumn{9}{|l|}{$\begin{array}{l}\text { Colorecta } \\
\text { I }\end{array}$} \\
\hline \multirow[t]{2}{*}{ Wales } & England & 74.7 & 1.1 & - & - & - & - & 74.7 \\
\hline & Manitoba & 82.1 & 8.5 & - & - & - & - & 82.1 \\
\hline \multirow{6}{*}{$\begin{array}{l}\text { Original } \\
\text { one-year } \\
\text { survival: } \\
73.6 \% \text { (A) }\end{array}$} & NSW & 84.7 & 11.1 & 0.4 & - & - & 0.4 & 84.3 \\
\hline & NI & 76.2 & 2.6 & - & - & - & - & 76.2 \\
\hline & Norway & 82.4 & 8.8 & 2.7 & - & - & 2.7 & 79.7 \\
\hline & Ontario & 83.9 & 10.3 & 0.4 & - & 1.9 & 2.3 & 81.6 \\
\hline & Sweden & 83.8 & 10.2 & 0.4 & 3.3 & - & 3.7 & 80.1 \\
\hline & Victoria & 85.1 & 11.5 & - & - & - & - & 85.1 \\
\hline \multicolumn{9}{|l|}{ Lung } \\
\hline \multirow[t]{2}{*}{ Wales } & England & 29.7 & 1.2 & - & - & - & - & 29.7 \\
\hline & Manitoba & 42.7 & 14.2 & - & - & - & - & 42.7 \\
\hline \multirow{6}{*}{$\begin{array}{l}\text { Original } \\
\text { one-year } \\
\text { survival: } \\
28.5 \% \text { (A) }\end{array}$} & NSW & 42.9 & 14.4 & 1.1 & - & - & 1.1 & 41.8 \\
\hline & NI & 30.6 & 2.1 & - & - & - & - & 30.6 \\
\hline & Norway & 39.2 & 10.7 & 7.3 & - & - & 7.3 & 31.9 \\
\hline & Ontario & 43.4 & 14.9 & 1.1 & - & 6.2 & 7.3 & 36.1 \\
\hline & Sweden & 43.6 & 15.1 & 1.1 & 3.5 & - & 4.6 & 39.0 \\
\hline & Victoria & 42.7 & 14.2 & - & - & - & - & 42.7 \\
\hline \multicolumn{9}{|l|}{ Ovary } \\
\hline \multirow[t]{2}{*}{ Wales } & England & 65.4 & 4.9 & - & - & - & - & 65.4 \\
\hline & Manitoba & 68.0 & 7.5 & - & - & - & - & 68.0 \\
\hline \multirow{6}{*}{$\begin{array}{l}\text { Original } \\
\text { one-year } \\
\text { survival: } \\
60.5 \% \text { (A) }\end{array}$} & NSW & 73.3 & 12.8 & 0.5 & - & - & 0.5 & 72.8 \\
\hline & NI & 63.9 & 3.4 & - & - & - & - & 63.9 \\
\hline & Norway & 75.2 & 14.7 & 2.6 & - & - & 2.6 & 72.6 \\
\hline & Ontario & 75.9 & 15.4 & 0.5 & - & 1.8 & 2.3 & 73.6 \\
\hline & Sweden & $\begin{array}{l}\text { Data not } \\
\text { supplied }\end{array}$ & - & - & - & - & - & - \\
\hline & Victoria & 73.7 & 13.2 & - & - & - & - & 73.7 \\
\hline
\end{tabular}

Table 6. Simulated change in one-year survival gap specific to ICBP jurisdictions prior to 2010, compared to Wales (jurisdiction with the lowest survival across all tumours sites). Percentage point change/errors summated to calculate adjusted 1-year survival. Based on NCRAS, Eastern Office 2010 data and ICBP Module 1 data $^{8}$ covering tumours diagnosed 2005-2007. ICBP Module 1 did not include ovarian cancer survival data from Sweden, as such no other registration practice figures are included here.

(X)- Figures from Table 1, (Y) - figures from Table 3, (Z) - figures from Table 5. 
ICBP Module 5 - Workstream 1, Part 2 


\section{Methods for identification of DCOs}

- Wales - Multiple data sources

- Scotland - received all death certificates cancer and non-cancer. Cancer cases are chased up by outsourced staff. Used to notify cases and update vital status.

- Norway - all deaths reported - run through semi-automatic coding process selecting underlying cause of death as per WHO guidelines. Trace back can occur via multiple data sources (clinical, pathology for example).

- Victoria - receives copies of each death certificate that are then linked to cancer registry database and coded as per the World Health Organisation guidelines. Cases unknown to registry become potential DCOs ( $\mathrm{pDCO}$ ). Coders then attempt to identify the missed notification (cannot approach certifying doctor or nursing homes)

- Ontario - separation between old (up to 2009) and new registry. Both cases received electronic file from Ontario Registrar General Office containing coded COD for each year. Patients accessioned with COD attributed to cases regardless of cancer or not. Old registry would allow DCOs if patient not already on system (new person, AND new cancer). New registry allows for all patients uf COD different from accessioned cancer case as per SEER/NCI multiple primary rules. All these processes are automated. Can manually review in the new registry, particularly cases that remain DCOs.

\section{Is death certificate notification mandatory?}

- England - Routine function of cancer registration practice

- Wales - Routine function of cancer registration practice

- Scotland, Victoria, NSW - yes

- Norway - mandatory by doctors - forwarded to Norwegian Institute of Public Health

- Ontario - No -working on a data sharing agreement so there is a risk of potential DCs to be withheld or restricted.

\section{Estimated proportion of not known/reported death certificates/death cards}

- England - 2.6\% (regional variation $0.1 \%$ to $4.1 \%$ )

- Wales - Males $1.2 \%$, Females $1.6 \%$

- Scotland-zero/negligible

- Northern Ireland $-0.3 \%$

- Norway - 1.7\%. 683 absolute cases in 2013, 732 in 2014. 1/3 related to death abroad

- New South Wales $-1.4 \%$

- Victoria - small (not measured)

- Manitoba $-0.5 \%$

- Ontario - $2.0 \%$ (no active trace back if DCO proportion less than or equal to $2 \%$ )

4. Is there central recording/collection of death certificates?

- England - Feed of cancer deaths from Office for National Statistics (ONS)

- Wales - weekly feed of cancer deaths from ONS

- Scotland - National records of Scotland

- Norway - Norwegian Institute of Public Health

- Victoria - coded by Australian Bureau of Statistics

- NSW - coded by Australian Bureau of Statistics

- Ontario - Yes from Ontario Register General Office

5. Methods and completeness for tracing back DCOs to produce DCls including:

a) Who is responsible for performing this?

- England - cancer registrars interrogate all available sources. This may be cross checked with the clinical lead.

- Wales - the cancer registrars interrogate all available data sources

- Norway - Abstracters at the cancer registry. 
- Victoria - Cancer coders/registrars as part of routine practice

- NSW - Cancer information and analysis unit in conjunction with the registry

- Ontario - No active follow back as DCO rate $<2 \%$ and within national targets.

b. How quickly are they integrated into registry data?

- England - recived monthly and processed on an annual basis.

- Wales - received weekly and processed routinely (monthly)

- Scotland - batched every quarter with linkage to registry 6 months later to allow other corroborating sources of information to materialise

- Norway - September the following year

- Victoria - prior to publication of each incidence year

- NSW - Coded and loaded at the same time as other DCs for that year.

- Ontario -2 to 3 times a year.

c. What proportion of initial DCOs can be traced back to produce a $\mathrm{DCl}$ ?

- England-99\%

- Wales - information not available

- Norway-98.1\%

- Victoria - at least $60 \%$ of pDCOs end up with full registration - not sure of exact numbers

- NSW - unable to provide data - needed clarification of DCI definition

- Ontario - No active trace back

Supplementary material 3 - Detail obtained on death certificate handling in some jurisdictions.

Results from a key informant exercise 
ICBP Module 5 - Workstream 1, Part 2

Breast

100
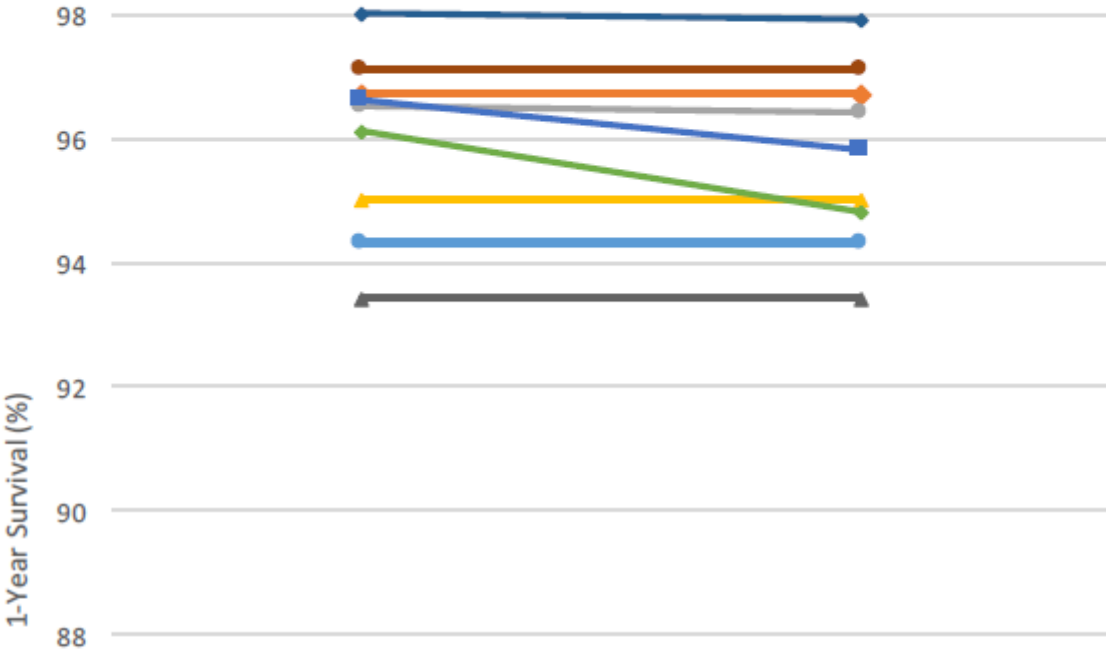

86

84

82

80

Unadjusted

Adjusted

$\longrightarrow$ England $\longrightarrow$ Manitoba $\longrightarrow$ NSW $\longrightarrow$ NI
$\longrightarrow$ Ontario $\longrightarrow$ Sweden $\longrightarrow$ Victoria $\longrightarrow$ Wales

- Norway 
ICBP Module 5 - Workstream 1, Part 2

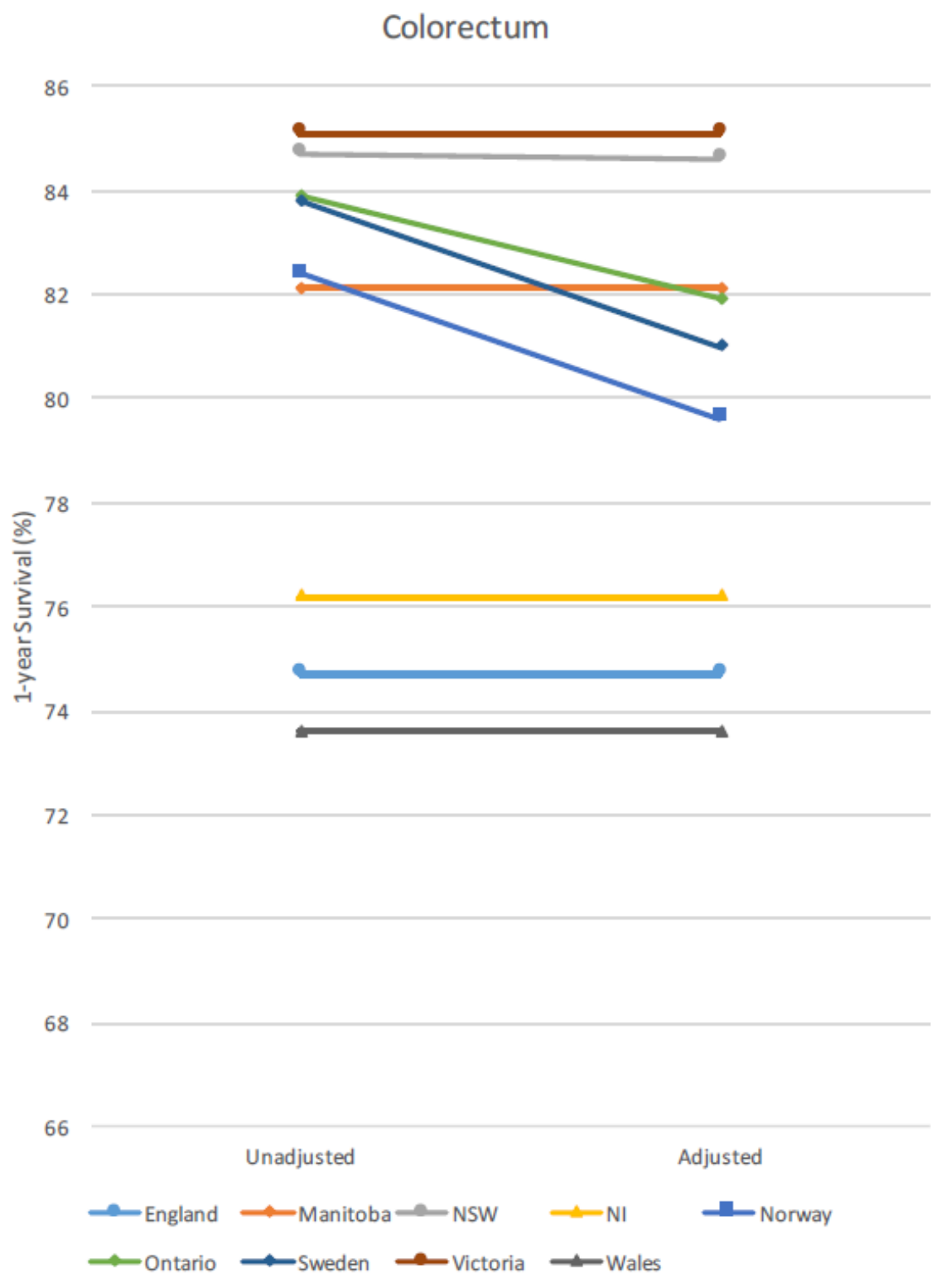


ICBP Module 5 - Workstream 1, Part 2

Lung

45

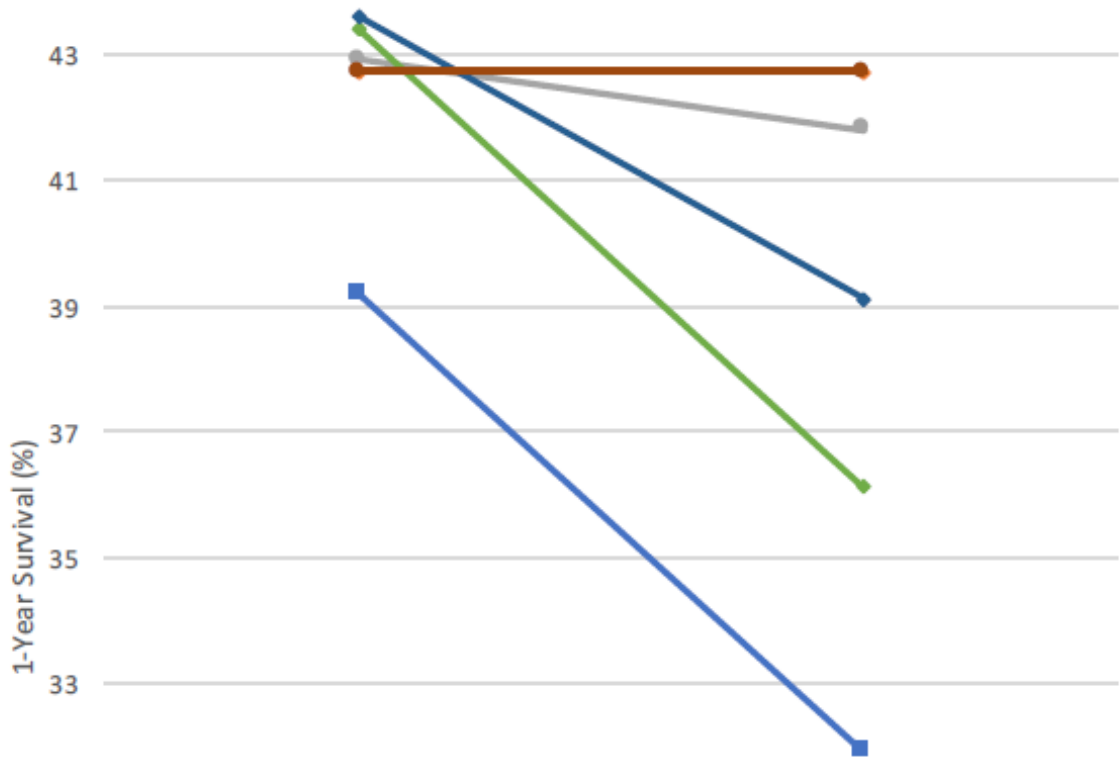

31

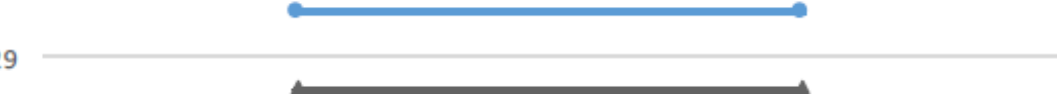

27

25

Unadjusted

Adjusted

$\longrightarrow$ England

$\sim$ Manitoba $\because$ NSW

$\longrightarrow \mathrm{NI}$

- Norway

$\rightarrow$ Ontario

$\rightarrow$ Sweden

$\longrightarrow$ Victoria

$\longrightarrow$ Wales 
ICBP Module 5 - Workstream 1, Part 2

\section{Ovary}

80

78
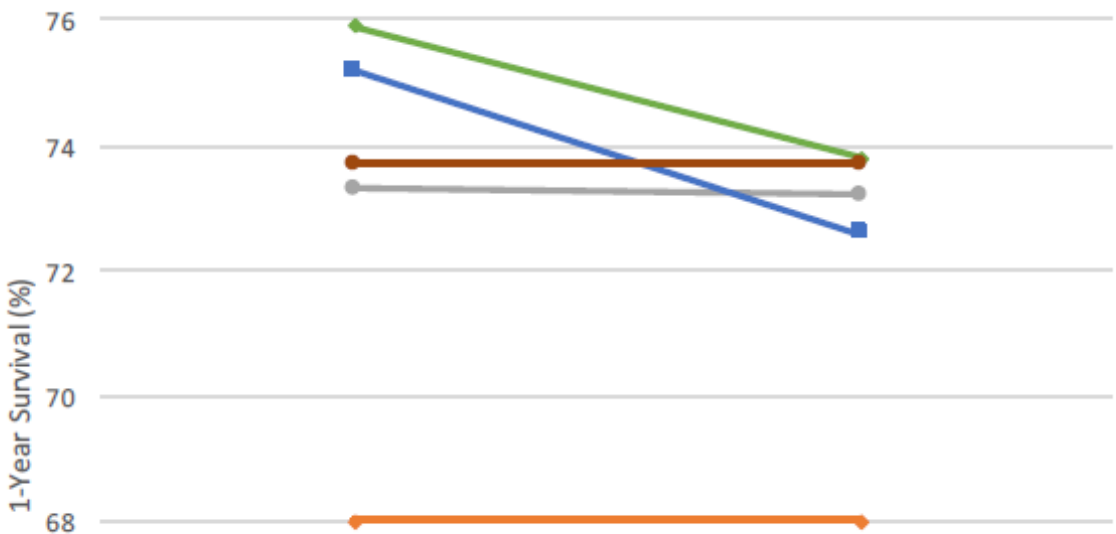

66

64

62

60

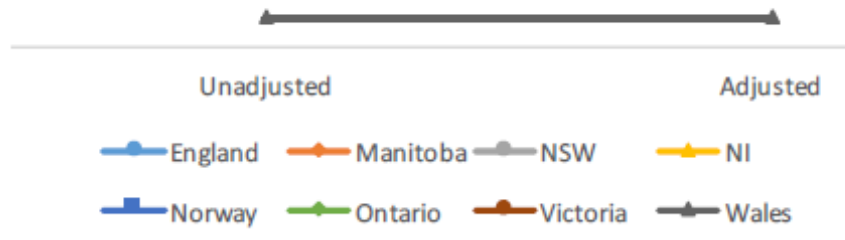

Figure 2: Adjusted and unadjusted 1-year survival estimates calculated in Table 8 by tumour site and jurisdiction. Note: $y$-axis has been truncated for each cancer site. (Adjustment is made taking into account differences in DCO handling, prioritised date of diagnosis and registration of multiple tumours.) 